\title{
Antioxidant and Antimicrobial Efficacy of Various Solvent Extracts of Seed of Rudrakshya (Elaeocarpus ganitrus) from Ilam District of Nepal
}

\author{
Bishan Datt Bhatt*, Purushottam Dahal \\ Department of Chemistry, Tri-Chandra Multiple Campus, Tribhuvan University, Kathmandu, Nepal \\ *Corresponding E-mail: bdbhatta@gmail.com \\ (Received: Sept. 30, 2019; Revised: Dec. 21, 2019 \& Accepted: Dec. 22, 2019)
}

\begin{abstract}
Elaeocarpus ganitrus (Rudrakshya) is an evergreen tree found in tropical and sub-tropical regions and has been commonly used in traditional medicine against various diseases. In the present study, phytochemical constituents, antimicrobial activity and antioxidant property of seed of Elaeocarpus ganitrus have been evaluated in hexane, ethyl acetate, acetone and methanol extracts. The phytochemical screening showed the presence of alkaloids, flavonoids, phenols, tannins, steroids, carbohydrates, saponins, terpenoids etc. The antibacterial test showed a significant zone of inhibition against Escherichia coli, Salmonella typhi and Staphylococcus aureus with the maximum zone of inhibition of $20 \mathrm{~mm}$. The study showed that these extracts can be used as antimicrobialsubstances against various bacteria. Antioxidant activity of the methanol, acetone and ethyl acetate extract were studied by DPPH radical scavenging assay. The extracts showed significant antioxidant activity. Among the $\mathrm{IC}_{50}$ values of different extractson DPPH assay for antioxidant determination, methanol seed extract showed the lowest value of $28.09 \mu \mathrm{g} / \mathrm{mL}$. This means methanol extract of seed showed the significantly high antioxidant properties. Calculation of total phenolic content showed a significant amount of phenolic content in different solvent extracts. Methanol seed extract showed the highest total phenolic content of $174.6 \mathrm{mgGAE} / \mathrm{g}$. Similarly, methanol seed extract showed the highest total flavonoid content of $107.13 \mathrm{mgQE} / \mathrm{g}$. These results suggest that the seeds of the Elaeocarpus ganitrus (Rudrakshya) plant from the Ilam district of Nepal possess high antimicrobial and antioxidant properties and thus, the plant can be used in the discovery of new bioactive natural products.
\end{abstract}

Keywords: Antibacterial, antioxidant, Elaeocarpus ganitrus, phytochemical analysis.

\section{Introduction}

Elaeocarpusganitrus belongs to family Elaeocarpeceae, and it generally grows in the Himalayan region. It is commonly known Rudrakshya in Nepal. The family Elaeocarpeceae has about 360 species and is mainly found in Nepal, India, Australia, Indonesia and East Asia. About 120 species of Elaeocarpus are found in Asia, among which Elaeocarpus ganitrus is one of the important species with high medicinal value [1]. It is an evergreen tree found in tropical and sub-tropical regions at the altitude up to 2000 meters from sea level. The height of Rudrakshya tree ranges from 50200 feet with large sized green leaves [2].

Elaeocarpus ganitrus is a common perennial tree which grows on tropical, sub-tropical and hilly region of Nepal and other countries including India,
Malaysia, China, Japan, Australia, Newzealand, Fiji and Hawaii [3]. In Nepal, it is widely distributed in Eastern hilly and terai districts like Ilam, Pachthar, Jhapa, Morang, Dhankuta, Sankhwasabha, Bhojpur, Terhathum etc.It is a large evergreen broad-leaved tree which grows in the area of gangetic plain to the foothills of high Himalaya. Tree has a pyramidal shape and starts giving fruit in seven years. The mature fruit is a drupe and stone beads are enclosed by an outer shell which is blue colored on ripening and hence they are also called blueberry beads. Beads are hard in nature. Elaeocarpus ganitrus grows in a suitable climatic condition of temperature ranging from $20-30{ }^{\circ} \mathrm{C}$.

According to Hindu mythology, Rudrakshya bead bears a great religious, spiritual and materialistic 
significance. The Hindu mythology considers Rudrakshya as the symbol of linkage between the earth and heaven and is believed to contain the secrets of the evolution of cosmos within itself [4]. It has a significant position in the Hindu religion and in Ayurveda, the ancient Hindu system of medicine. Elaeocarpus ganitrus is the king of herbal medicine working effectively and has many spiritual and medicinal values both as defensive and remedial. It is used in folk medicine in treatment of stress, anxiety, depression, palpitation, nerve pain, epilepsy, migraine, lack of concentration, asthma, hypertension, arthritis, liver diseases and is effective antimicrobial agent [5].

Elaeocarpus ganitrus is a source of various pharmacologically and medicinally significant chemicals such as triterpenes, tannins like geranin and 3,4,5-trimethoxy geranin, indolizilidine alkaloids, grandisines, rudrakine, and flavonoid quercetin [6]. Elaeocarpus ganitrus plant, having ethno medicinal claims with regard to their phytoconstituents, pharmacological profile and other allied activities, has been claimed to exhibit antiaging, antianxiety, antidepressant, antidiabetic, anti-inflammatory, sedative, anticonvulsive, antihypertensive and antimicrobial properties. The beads of Elaeocarpus ganitrus helps in therapeutic healing of body diseases chronically due to its electromagnetic properties also by virtue of acupressure and bio magnetic therapy and piezoelectric consequences. It has the ability to generate an electric charges in the response to applied mechanical stress [7]. The beads, bark and leaves of Elaeocarpus ganitrus have immense importance in the Ayurvedic medicine system and have been described to cure ailments like mental disorder, headache, fever, skin diseases, palpitation, insomnia, infertility etc [8]. The bark of the Elaeocarpus ganitrus found to contain various bioactive metabolites, responsible for its various medicinal uses [9]. Elaeocarpus ganitrus beads help in the therapeutic healing of various body diseases due to its electromagnetic property [10]. It is an important medicinal plant with several curative properties, that's why it is used in traditional systems of medicine [11].

Despite so many applications of the plants, no extensive studies on evaluation of phytochemicals, and study on the relation of various phytochemicals with their bioactivity efficacy, have been done from the seeds of Nepal specially Ilam district. Also, there is no comparative investigation in the biological efficacy of extracts in different solvents like hexane, ethyl acetate, acetone and methanol. The present study aims to evaluate the various phytochemicals, total phenolic content, total flavonoid content, antimicrobial activity and antioxidant property of various solvent extracts of seed of this useful plant of Ilam district. The study will be utilized to correlate the total phenolic and flavonoid contents and phytochemical screening with its antimicrobial and antioxidant efficacy.

\section{Materials and Method}

\section{Collection of plant materials}

The seeds of Elaeocarpus ganitrus were collected,in the month of June, from Rong rural municipality of the Ilam district, Nepal. They were then washed shade dried and crushed into a fine powder using mortar.

\section{Extraction of plant materials}

The powdered seed was extracted using soxhlet extractor in the solvent hexane, ethyl acetate, acetone and methanol successively at $30^{\circ} \mathrm{C}$. Then the sample was collected separately, evaporated using a rotatory evaporator and the dry extract was used for further study.

\section{Phytochemical analysis}

The dry extract was analyzed by color reactions, different phytochemicals were studied and the presence of different groups of phytochemicals was noted.

\section{Antibacterial activity}

The activity of various bioactive compounds from the plants has led to the discovery of new medicinal drugs. Antibacterial activity of the plant extract was performed by agar well diffusion method. The effectiveness of antimicrobial activity was evaluated by determining the zone of inhibition. The microbial strains obtained from MED-MICRO Nepal laboratory Kathmandu were inoculated in agar medium. The studied strains include a Gram-positive bacterium (Staphylococcus aureus ATCC 25923) Cocci-grapes like structure, a Gram negative bacterium (Escherichia coli ATCC 25922) short rod shape structure and another Gram-negative bacterium (Salmonella typhi) pink in color. Six wells were made in each incubated media plates with the help of sterile cork borer no. 6 . Sothe diameter of the well was $6 \mathrm{~mm}$ and was labeled 
properly. Then $50 \mu \mathrm{L}$ of the working solution of the plant extract, DMSO as the negative control $(\mathrm{Nc})$ and $25 \mu \mathrm{L}$ of Ofloxacin (antibiotic- ear and eye drop) as the positive control $(\mathrm{Pc})$ at the same time in separated well were loaded into the respective wells with the help of micropipette. The plates were subsequently left for half an hour with the lid closed so that the extract diffused into the media. The plates were incubated for 24 hours at $37{ }^{\circ} \mathrm{C}$. After 24 hours of incubation, the plates were observed for the presence of inhibition of bacterial growth which was indicated by a clear zone around the wells. The size of the zone of inhibition was measured and the antibacterial activity was expressed in terms of the average diameter of the zone of inhibition in millimeters. The absence of the zone of inhibition was interpreted as the absence of the activity. The zone of inhibition (ZOI) was measured with the help of a millimeter ruler and the mean was recorded.

\section{Antioxidant activity}

The numerous methods used to measure the antioxidant activity of the plants can give varying results depending on the specific free radical being used as a reactant. An efficient method to measure antioxidant capacity involves the use of the free radical, 2, 2-diphenyl-1-picrylhydrazyl (DPPH). The antioxidant capacity of ethyl acetate extract, acetone extract and methanol extract were evaluated using standard DPPH assay [12]. The percentage of DPPH free radical scavenging activity was calculated by using the following equation:

Radical scavenging $(\%)=\left[\left(\mathrm{A}_{\mathrm{o}}-\mathrm{A}_{\mathrm{s}}\right) / \mathrm{A}_{\mathrm{o}}\right] \times 100$

Where, $\mathrm{A}_{\mathrm{o}}=$ Absorbance of the control (DPPH solution + methanol),

$\mathrm{A}_{\mathrm{s}}=$ Absorbance of the test sample

The $\mathrm{IC}_{50}(50 \%$ inhibitory concentration) value is indicated as the effective concentration of the sample which is required to scavenge $50 \%$ of the $\mathrm{DPPH}$ free radicals. $\mathrm{IC}_{50}$ values were calculated using the inhibition curve by plotting extract concentration versus the corresponding scavenging effect.

\section{Preparation of the $0.2 \mathrm{mM}$ DPPH solution}

DPPH has a molecular mass of $394.32 \mathrm{~g} / \mathrm{mol}$. Thus, $100 \mathrm{~mL}$ of $0.2 \mathrm{mM}$ solution of DPPH was prepared by weighing the $0.0078 \mathrm{~g}$ of the DPPH carefully and dissolving it on methanol and finally maintaining the volume to $100 \mathrm{~mL}$. The solution was kept in dark place until the use. Different concentrations of test samples of $20,40,60,80$ and $100 \mu \mathrm{g} / \mathrm{mL}$ were made from stock solutions. Then $2 \mathrm{~mL}$ of all the test solutions were mixed to $2 \mathrm{~mL}$ of DPPH solution. The test tubes were shaken vigorously for the uniform mixing and the solutions were kept for 30 minutes in the dark place at room temperature. The control was prepared by mixing methanol and DPPH solution without the plant extracts (methanol + DPPH). After 30 minutes, the absorbance of the entire sample was measured at $517 \mathrm{~nm}$ using a UV-visible spectrophotometer. The ascorbic acid of the same concentration was prepared as a standard and its absorbance was also taken spectrophotometrically at $517 \mathrm{~nm}$ and the calibration curve was constructed. Using ascorbic acid as the positive control, the percent radical scavenging activity was determined by comparison with the methanol treated control group.

\section{Total phenolic content (TPC) determination}

The total phenolic content of all selected plant extracts were estimated using Folin-Ciocalteu reagent involving gallic acid standard based on oxidationreduction reaction. The procedure carried out for the total phenol content was based on the standard procedure using gallic acid as standard. Gallic acid stock solution was prepared by dissolving $10 \mathrm{mg}$ of gallic acid in $1 \mathrm{~mL}$ of methanol. Various concentrations of gallic acid such as 20,40,60, 80 and $100 \mu \mathrm{g} / \mathrm{mL}$ were prepared. An aliquot of $1 \mathrm{~mL}$ gallic acid of each concentration in methanol was poured to a $20 \mathrm{~mL}$ test tube. To that $5 \mathrm{~mL}$ of folin-ciocalteau (FCR) $(10 \%$, $1: 10 \mathrm{v} / \mathrm{v}$ diluted in distilled water) and $4 \mathrm{~mL}$ of $7 \%$ $\mathrm{Na}_{2} \mathrm{CO}_{3}$ were added to get a total volume of $10 \mathrm{~mL}$. The blue-colored solution was shaken well and then incubated for 30 minutes at $40{ }^{\circ} \mathrm{C}$ in a water bath. After this, the absorbance was accurately measured at $760 \mathrm{~nm}$ against a blank containing all reagents except gallic acid. The average absorbance values obtained at these different concentrations of gallic acid were used to plot the calibration curve. By the serial dilutions, samples with the concentrations of 20, 40, 60, 80 and $100 \mu \mathrm{g} / \mathrm{mL}$ were prepared. To these diluted solutions, $10 \% \mathrm{FCR}$ and $7 \% \mathrm{Na}_{2} \mathrm{CO}_{3}$ were added and incubated for 30 minutes as in the case of gallic acid and absorbance was measured at $760 \mathrm{~nm}$ against blank for each concentration. 


\section{Total flavonoid content (TFC) determination}

Total flavonoid content of the seed extracts was determined according to the aluminum chloride colorimetric method involving quercetin as standard [13]. Quercetin stock solution was prepared by dissolving $10 \mathrm{mg}$ of quercetin in $1 \mathrm{~mL}$ of methanol. Various concentrations of quercetin such as 20,40, 60,80 and $100 \mu \mathrm{g} / \mathrm{mL}$ were prepared. An aliquot of 1 $\mathrm{mL}$ quercetin of each concentration in methanol was poured to $20 \mathrm{~mL}$ test tube containing $4 \mathrm{~mL}$ of doubledistilled water. At the zero time, $0.3 \mathrm{~mL} 5 \% \mathrm{NaNO}_{2}$ was added to the test tube. After a minute, $0.3 \mathrm{~mL}$ of $10 \% \mathrm{AlCl}_{3}$ was added. After 6 minutes, $2 \mathrm{~mL}$ of $1 \mathrm{M} \mathrm{NaOH}$ was added to the mixture. Immediately, the total volume of the mixture was made up to 10 $\mathrm{mL}$ by the addition of $2.4 \mathrm{~mL}$ of double distilled water and mixed thoroughly. The absorbance of the pink color mixture was determined at $510 \mathrm{~nm}$ versus blank containing all the reagents except quercetin. All the experiments were carried out in triplicate. The average absorbance values obtained at different concentrations of quercetin were used to plot the calibration curve. The stock solutions of all the extracts were prepared by dissolving $10 \mathrm{mg}$ in $1 \mathrm{~mL}$ of methanol $(10 \mathrm{mg} / \mathrm{mL})$. Serial dilutions were carried out to get the concentration of $20,40,60,80$ and 100 $\mu \mathrm{g} / \mathrm{mL}$. Following the procedure as for quercetin as described above, absorbance for each concentration of the extract was measured at $510 \mathrm{~nm}$.

\section{Results and Discussion}

\section{Phytochemical analysis}

Different phytochemical constituents present in the extract were identified by the color reaction with different reagents following the standard phytochemical screening methods. The main objective of phytochemical screening was to identify the different groups of chemical constituents present in the different plant extracts. The screening of phytochemicals showed the presence of alkaloids, carbohydrates, flavonoids, terpenoids, lactones, tannins, phenols, quinines, etc. The main phytochemicals obtained as a result of the phytochemical screening of the seed of Elaeocarpus ganitrus are summarized in table 1.

The above results show the presence of several important phytochemicals in nearly all the extracts. Moreover, acetone and methanol extracts have been found to contain most of the phytochemicals under study. These results show that the plant can be used as a potential source of several natural products.

Table1: Phytochemical constituents of different solvent extracts of seed of Elaeocarpus ganitrus.

\begin{tabular}{|c|c|c|c|c|c|c|}
\hline S.N & Phytochemicals & Name of test & H. E & E.E & A.E & M.E \\
\hline \multirow[t]{3}{*}{1} & Alkaloids & a) Mayer's test & - & + & + & + \\
\hline & & b) Wagner's test & + & + & + & + \\
\hline & & c)Dragendroff's test & - & + & + & + \\
\hline \multirow[t]{2}{*}{2} & Carbohydrates & a) Fehling's test & + & + & + & + \\
\hline & & b) Molisch's test & + & + & + & + \\
\hline \multirow[t]{2}{*}{3} & Glycosides & a) Alkaline reagent test & + & + & + & + \\
\hline & & b) Legal test & + & + & + & + \\
\hline \multirow[t]{2}{*}{4} & Lactones & a) Kedde test & + & + & + & + \\
\hline & & b)Baljel test & + & + & + & + \\
\hline \multirow[t]{2}{*}{5} & Proteins \& & a) Xanthoprotic test & - & - & - & - \\
\hline & Amino acids & b) Biuret test & _ & _- & _- & _- \\
\hline 6 & Fatty acids & a) Spot test & - & + & + & + \\
\hline \multirow[t]{3}{*}{7} & Flavonoids & a) Shinoda test & + & + & + & + \\
\hline & & b) Shibata test & + & + & + & + \\
\hline & & c) Lead acetate test & + & + & + & + \\
\hline 8 & Steroids & a) Salkowski test & + & - & + & + \\
\hline \multirow[t]{2}{*}{9} & Terpenoids & a) Salkowski test & + & + & + & + \\
\hline & & b) Tschugajen test & + & + & + & + \\
\hline 10 & Saponins & a) Froth test & - & - & + & + \\
\hline 11 & Tannins & a) Lead acetate test & + & + & + & + \\
\hline 12 & Phenols & a) Braymerm test & + & + & + & + \\
\hline 13 & Phlabotannins & a) Precipitate test & - & - & - & - \\
\hline 17 & Anthraquinones & a) Alkaline reagent test & + & + & + & + \\
\hline 18 & Quinones & a) Brontiager test & + & + & + & + \\
\hline
\end{tabular}

H.E $=$ Hexane extract, E.E $=$ Ethyl acetate extract, A.E=Acetone extract, M.E=Methanol extract, $(+)=$ Presence, $(-)=$ Absence 
Table 2: Antibacterial analysis of hexane, ethyl acetate, acetone and methanol extracts of seed of Elaeocarpus ganitrus.

\begin{tabular}{|c|c|c|c|c|c|}
\hline S.N & Plant extract & Bacteria & \multicolumn{2}{|c|}{$\begin{array}{l}\text { ZOI of extract } \\
1 \% 10 \%\end{array}$} & $\begin{array}{l}\text { ZOI of } \\
\text { ofloxacin }\end{array}$ \\
\hline \multirow[t]{3}{*}{1} & Hexane & S. aureus & 0 & 8 & 32 \\
\hline & Extract & E. coli & 9 & 12 & 30 \\
\hline & & S. typhi & 0 & 8 & 22 \\
\hline \multirow[t]{3}{*}{2} & Ethyl acetate & S. aureus & 0 & 12 & 34 \\
\hline & Extract & E. coli & 12 & 12 & 30 \\
\hline & & S. typhi & 0 & 15 & 25 \\
\hline \multirow[t]{3}{*}{3} & Acetone & S. aureus & 8 & 10 & 33 \\
\hline & Extract & E. coli & 12 & 12 & 30 \\
\hline & & S. typhi & 18 & 20 & 23 \\
\hline \multirow[t]{3}{*}{4} & Methanol & S. aureus & 8 & 10 & 32 \\
\hline & Extract & E. coli & 13 & 16 & 30 \\
\hline & & S. typhi & 18 & 20 & 22 \\
\hline
\end{tabular}

Table 3: Absorbance values of ethyl acetate, acetone and methanol extracts of the seed of Elaeocarpus ganitrus measured at $517 \mathrm{~nm}$ in the DPPH assay.

\begin{tabular}{llllll}
\hline S.N & Samples & $\begin{array}{l}\text { Concentration } \\
(\boldsymbol{\mu g} / \mathbf{m L})\end{array}$ & Absorbance & \% inhibition & $\mathbf{I C}_{\mathbf{5 0}}$ \\
\hline 1. & Ethyl acetate & 20 & 0.2756 & 60.43 & 35.65 \\
& extract & 40 & 0.2393 & 65.64 & \\
& & 60 & 0.2079 & 70.15 & \\
& 80 & 0.1454 & 79.12 & \\
& & 0.1156 & 83.40 & \\
2. & 100 & & & 36.72 \\
& Acetone & 20 & 0.2602 & 62.64 & \\
& extract & 40 & 0.2432 & 65.08 & \\
& & 60 & 0.2241 & 67.82 & \\
& & 80 & 0.1854 & 73.38 & \\
& & 100 & 0.1295 & 81.40 & \\
3. & & & & \\
& Methanol & 20 & 0.2288 & 67.14 & \\
& extract & 40 & 0.1741 & 75.00 & \\
& & 60 & 0.1452 & 79.14 & \\
& & 80 & 0.1205 & 82.69 & \\
\hline
\end{tabular}




\section{Antibacterial Activity}

The zone of inhibition (ZOI) produced by the plant extract on particular bacteria was measured for the estimation of its antibacterial activity. Zone of inhibition created by hexane, ethyl acetate, acetone and methanol extracts were studied and their effects against Gram-positive bacteria Staphylococcus aureus and Gram-negative bacteria Escherichia coli and Salmonella typhi were evaluated. Results obtained from the antibacterial analysis of different extracts have been tabulated in table 2 .

The above result shows that the acetone and methanol extracts exhibit significant antimicrobial activities against bacteria under investigation. Acetone and methanol extracts have been found highly effective against $S$. typhi.

\section{DPPH free radical scavenging activity}

In this study, the antioxidant activity of each plant extract was measured by using 1,1-diphenyl-2-picryl hydrazyl radical (DPPH). In this assay, the mixture of DPPH with different concentrations of extract solutions and ascorbic acid were separately incubated at room temperature and absorbance was recorded at $517 \mathrm{~nm}$ by a spectrophotometer. The calibration curve was constructed by measuring the absorbance of ascorbic acid in order to calculate the $\mathrm{IC}_{50}$ value. The value obtained from plant extract was compared with ascorbic acid. The observed absorbance values with the different concentrations have been tabulated in table 3 and graphically represented in figure 1 .

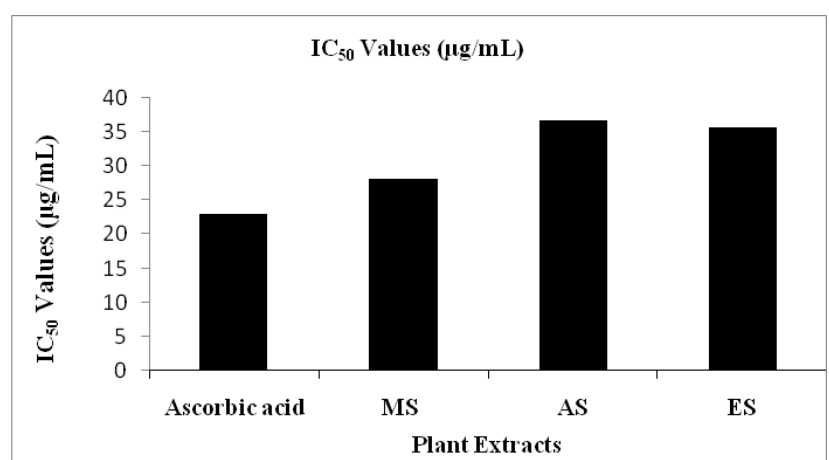

$(\mathrm{MS}=$ Methanol seed, $\mathrm{AS}=$ Acetone seed, $\mathrm{ES}=$ Ethyl acetate seed.)

Figure 1: A bar diagram of $I C_{50}$ values of different seed extracts of Elaeocarpus ganitrus and ascorbic acid
The above results show that the methanol extract is found to contain the lowest $\mathrm{IC}_{50}$ value, which is close to the value of ascorbic acid. This result shows its efficacy as a good antioxidant.

\section{Total phenolic content (TPC)}

The TPC in plant extract was estimated by using the FCR colorimetric method based onoxidation reduction reaction. Gallic acid was used as a standard compound for the construction of calibration curve. The TPC values of different extracts have been depicted in table 4.

Table 4: Total Phenolic content of different solvent extracts of Elaeocarpus ganitrus seed.

\begin{tabular}{clll}
\hline S. N. & Sample & Extract & TPC(mgGAE/g) \\
\hline 1 & AS & Acetone Seed & 146.15 \\
2 & ES & Ethyl acetate Seed & 143.90 \\
3 & MS & Methanol Seed & 174.60 \\
\hline
\end{tabular}

More conveniently, total phenolic content in different plant extracts has been represented in the bar diagram in figure 2.

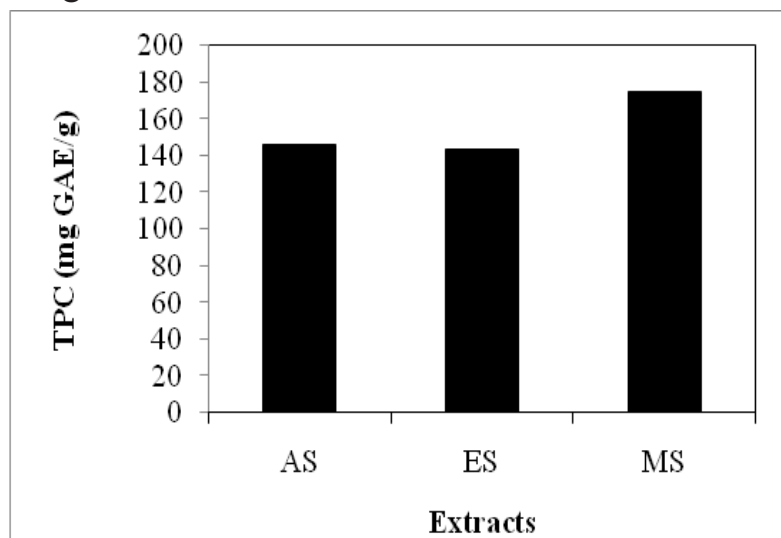

$(\mathrm{MS}=$ Methanol seed, $\mathrm{AS}=$ Acetone seed, $\mathrm{ES}=$ Ethyl acetate seed.)

Figure 2: Total phenolic content of seed of Elaeocarpus ganitrus in different solvents.

The result demonstrated that among the studied samples, the total phenolic content was the highest in the methanol extract, though all the extracts were found to contain a significant amount of phenolic contents. These TPC values match with the results obtained in phytochemical screening.

\section{Total flavonoid content (TFC)}

The aluminum chloride colorimetric assay was used for the estimation of total flavonoid present in the 
seed extract in a different solvent according to the standard procedure involving quercetin as standard. The flavonoids of the plant extracts in the presence of aluminum chloride forms an acid liable complex, has an intense yellow fluorescence which can be observed under UV spectrophotometer at $510 \mathrm{~nm}$. The intensity of light absorption at that wavelength is proportional to the concentration of flavonoids and was determined using quercetin as standard. The TFC values of different plant extracts ( $\mathrm{mg}$ quercetin equivalent per $\mathrm{g}$ dry extract) have been tabulated in table 5 .

Table 5: Total flavonoid content of different extracts of seed of Elaeocarpus ganitrus.

\begin{tabular}{clll}
\hline S. $\mathbf{N}$. & Sample & Extract & TFC $(\mathbf{m g Q E} / \mathbf{g})$ \\
\hline 1 & AS & Acetone Seed & 78.92 \\
2 & ES & Ethyl acetate Seed & 66.88 \\
3 & MS & Methanol Seed & 107.13 \\
\hline
\end{tabular}

The results have been represented as a bar diagram in figure 3.

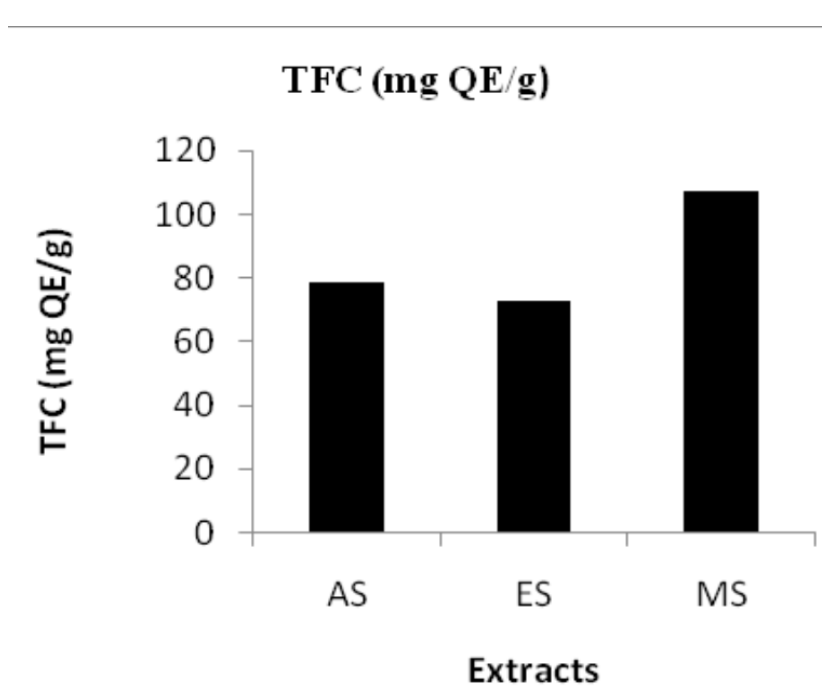

(MS=Methanol seed, $\mathrm{AS}=$ Acetone seed, $\mathrm{ES}=$ Ethyl acetate seed. $)$

Figure 3: Total flavonoid content of seed of Elaeocarpus ganitrus in different solvents.

The result demonstrated that among the studied samples, the total flavonoid content was highest in the methanol extract, followed by acetone extract of seed. Acetone and ethyl acetate extracts also showed a significant amount of total flavonoid content.

\section{Conclusion}

Phytochemical investigation of the seed extract of Elaeocarpus ganitrus showed the presence of various bioactive substances such as alkaloids, phenols and tannins, terpenoids, carbohydrates, quinones, flavonoids, glycosides in various solvents. These results show the use of this plant as a potential source of several bioactive natural products.

All the extracts of the seed of Elaeocarpus ganitrus showed significant antibacterial activity with different values of the zone of inhibitions. The methanol extract was found to be highly effective against Salmonella typhi. These results show the efficacy of the plant as a source of antimicrobial substances.

Methanol seed extract shows the low value of IC50 $(28.09 \mu \mathrm{g} / \mathrm{mL})$ in antioxidant DPPH assay which is close to that of ascorbic acid $(23.06 \mu \mathrm{g} / \mathrm{mL})$. A significant amount of total phenolic compound was obtained in the various extracts, methanol extract being highest with total phenolic content of 174.6 mgGAE/g extract. Similarly, the highest total flavonoid content $(107.13 \mathrm{mgQE} / \mathrm{g})$ was found in methanol seed extract. Other extracts also showed a significant amount of total phenolic content as well as total flavonoid content.

Different previous pharmacological studies in this plant show the presence of different phytochemicals and their antibacterial efficacy. The different zone of inhibitions in these studies may be due to the different areas of samples as well as different solvents used for extraction. Similarly, IC50 value $78-72 \mu \mathrm{g} / \mathrm{mL}$ in antioxidant DPPH assay [11] is slightly different than the present study, due to the difference in the geographical region, climatic condition as well as the time of sample collection.

In the present study, it has also been found that high antioxidant activity is shown by the extracts which have higher phenolic and flavonoid contents. Phenolic compounds and flavonoids play important role in antioxidant activity. These all the facts highly support the use of Elaeocarpus ganitrus (Rudrakshya) in the traditional medicinal system as well as in homemade medicines. 


\section{References}

1. H. Swati, B. B. Nandy and K. Kumar, Elaeocarpus ganitrus (Rudrakshya): A reservoir plant with their pharmacological effects, International Journal of Pharmaceutical Science, 2015, 34(1), 645-649.

2. S. Tripathy, A. Middhaa and S. Swain, Elaeocarpus ganitrus, the amazing electromagnetic bead of nature to redeem mankind from disease, sickness and medicinal problem, World Journal of Pharmacy and Pharmaceutical Science, 2016, 5(9), 1079-1099.

3. S. Hardainian, B. C. Nandy and R. Saxena, Phytochemical investigation of fruit extract of Elaeocarpus ganitrus, International Journal of Pharmacy and Pharmaceutical Sciences, 2015, 7(6), 415-418.

4. K. Pandey, M. Singh and A. Upadhyaya, Preliminary phytochemical screening and antimicrobial activities of plant extract of Elaeocarpus ganitrus, International Journal of Bioassay, 2016, 5(9), 4885-4889.

5. A. Tilak, S. Gangwar and R. N. Thakur, Preliminary phytochemical screening and antimicrobial activities of plant extract of Elaeocarpus ganitrus Roxb., Imperial Journal of Interdisciplinary Research, 2017, 3(1), 1531-1538.

6. T. J. Dennis, Rudrakshya- not just a spiritual symbol but also a medicinal remedy, Sachitra Ayurved, 1993, 46(2), 142-146.
7. H. N. Mastura and A. Germano, Plant alkaloids: main features, toxicity and mechanism of action, Researchgate, 2015, 10(7), 94-102.

8. L. Yang and J. Stocktigt, Trends for diverse production strategies of plant, medicinal alkaloids, Natural Product Report, 2010, 27(6), 1469-1479.

9. N. Talukdar, A. M. Dutta, R. Chakraborty and K. Das, Screening of phytochemicals, antioxidant and inhibitory effect on alpha-amylase by ethanolic extract of Elaeocarpus ganitrus bark, International Journal of Pharmaceutical Sciences and Research, 2017, 8(12), 5270-5275.

10. A. Tilak, S. Gangwar, and R. N. Thakur, Elaeocarpus ganitrus medicinal use in modern time, Imperial Journal of Interdisciplinary Research, 2017, 3(1), 1531-1538.

11. A. Marisetti and S. Kolli, In-vitro anti-oxidant and thrombolytic activity of Elaeocarpus ganitrus bark extracts, World Journal of Pharmacy and Pharmaceutical Sciences, 2016, 5(10),1312-1320.

12. W. B. Williams, M. E. Cuveliar and C. Berset, Use of free radical method to evaluate antioxidant activity, Food Science Technology, 1995, 28(1), 25-30.

13. M. Mazur and J. Telser, Free radicals and antioxidants in normal physiological functions and human disease, The International Journal of Biochemistry and Cell Biology, 2007, 39, 44-84. 